\title{
Knowledge Management Research on the Effectiveness of Case Teaching
}

\author{
Ying ZHENG ${ }^{1, a}$, Gao-Feng PAN ${ }^{2, b}$ \\ ${ }^{1,2}$ Aviation Theory Dept. of Aviation University of Air Force, Changchun, China. \\ asqf1998@163.com, bsqf1998@163.com
}

Keywords: Knowledge management, Case teaching, Effectiveness.

\begin{abstract}
Case teaching method, as a teaching method, is more of a kind of educational ideas and concepts and is an innovative teaching practice. This paper analyzes the case teaching method that plays a vital role in education and teaching; and from the perspective of knowledge management analyzes the unique advantages the teaching method has, and reveals the effective process in the case teaching that includes the promotion of knowledge sharing, knowledge conversion, thereby creating new knowledge.
\end{abstract}

\section{Introduction}

The main purpose of school education hopes students to get comprehensive growth through the process of teaching, and the growth includes personal knowledge system, learning ability and analyzing and solving problems ability. The effectiveness of teaching and learning activities is of course closely related to teachers' knowledge and the value of knowledge, but it can not be ignored that the key still lies in teaching modes, the students' willingness to learn and the level of their commitments.

The most commonly used teaching method is lecturing. Teacher leads most of the content and teaching activities, carrying effectively out important knowledge and concept to students in a manner of a systematic and structured way. However, students are passive to overall accept teachers' instructions and to complete homework before and after class.

In comparative study of the many teaching methods, classroom lecturing has been recognized as a way of teaching with less effectiveness. The causes of less effectiveness include: classroom lecturing is a unilateral teaching, lack of proper communication and interaction between teachers and learners, and the conveyed knowledge is difficult to combine with the students' willingness and learning progress.

\section{Case teaching is an effective way to meet the requirements of modern higher education}

The quality enhancement of higher education has become the focus of all walks of life. The ultimate point is the realization of classroom teaching effectiveness and its primary task is to reform of teaching methods, which conforms to the needs of training model innovation and responds to the talent needs of development. The utility of classroom case teaching method is the demand to develop students' personalization, and is the practice of capacity orientation of talents cultivation.

Traditional teaching mode is mainly based on the theory knowledge instruction. Although theoretical knowledge is also the accumulation and induction of experience and it can also play the role of guide for analyzing and solving problems, theoretical knowledge learned by students is blank and empty and can not produce the effect on the application if students can not make the learned theoretical knowledge system absorb into their thinking tank, and summarize a thinking mode that is helpful for solving problems. Especially to those students who lack practice, the theoretical knowledge they learned in the classroom, often turns into the memory of some of the terminology, recitation and meeting the test. They can not know the specific context of theoretical knowledge. There is no desired effect for the ability of analyzing problems and decision making. Therefore, the high quality of education must be beneficial to enhance the ability of students, must pursue maximized effectiveness of learning, and must make the growth of students the starting point.

Case teaching began in the early part of this century in the Harvard Business Institute. At that time, the Dean of the Business Institute, responding to business personnel training needing to be set in line with the 
actual operation of the teaching content and teaching methods, arranged in the course the business executives to school to teach enterprise operating experience and communicate with classmates. These courses greatly aroused students' interest in learning, so Harvard hoped valuable experience in business to develop into teaching materials by teachers, and by discussion and analysis in the classroom made students grow in the business analysis and decision making. After decades of development and the spread of teaching experience, it finally formed into a thriving Harvard case teaching of management.

Case teaching has a very significant effect on independent thinking, analysis of problems and linking theory with practice that education desires to reach. The so-called case teaching takes the specific facts that have once really happened as teaching materials. Through interactive discussion between teachers and students it explores the reasons for the occurrence, finds potential problems, and tries to propose some solutions.

The advantage of case teaching is that it uses real and concrete facts experience as teaching materials, which can allow students to vividly experience the true facts. At the same time, it requires students to take the initiative to explore, analyze, and determine the facts of experience and potential problems, which will help students to develop their analysis ability. Furthermore, case teaching takes the form of in and after class discussion to encourage students to express their views and opinions. The exchange of the type of discussion not only increases students' motivation to learn with the sense of participation, but also through discussion and exchange makes students experience to the analysis of the different angles of view, listen to the views of others, and through the judgment, finally consolidate to form their own point of view of decision making.

Of course, case teaching is not to entirely replace the traditional lecture-style teaching methods. A brief comparison of traditional teaching methods and case teaching methods is listed in Table 1. However, focusing on modern higher education's hoping to cultivate students' independent thinking and capacity of problem solving and analysis and decision making, case teaching does have its unique effects, and is therefore classified as a very important teaching method.

Table 1. A comparison between traditional teaching methods and case teaching method

\begin{tabular}{|c|c|c|c|c|c|c|}
\hline $\begin{array}{c}\text { Tradition } \\
\text { al } \\
\text { teaching }\end{array}$ & passivity & $\begin{array}{c}\text { inculcatio } \\
\mathrm{n}\end{array}$ & teaching & theory & $\begin{array}{c}\text { centered on } \\
\text { teachers }\end{array}$ & $\begin{array}{c}\text { little } \\
\text { interest }\end{array}$ \\
\hline $\begin{array}{c}\text { case } \\
\text { teaching }\end{array}$ & $\begin{array}{c}\text { participati } \\
\text { on }\end{array}$ & thinking & $\begin{array}{c}\text { discussio } \\
\mathrm{n}\end{array}$ & $\begin{array}{c}\text { practic } \\
\mathrm{e}\end{array}$ & $\begin{array}{c}\text { Centered } \\
\text { on students }\end{array}$ & $\begin{array}{c}\text { much } \\
\text { interest }\end{array}$ \\
\hline
\end{tabular}

\section{To reacquaint and discuss case teaching from the perspective of knowledge management}

Knowledge management is the new theory in the field of management. The pointing out of the concept of implicit knowledge makes us from a whole new perspective analyze and research all the connotation of knowledge management in case study pedagogy.

\section{Two types of knowledge}

The definition of explicit knowledge is the knowledge that can be spread through normal languages. The typical explicit knowledge exists in research papers, books, computer databases and CD-ROM, etc. Explicit knowledge can be expressed with material existence, and can be known with certainty. Implicit knowledge is defined as a deeper level, and individuals owned knowledge. It is impossible to spread to others or spreads with great difficulties. Implicit knowledge is difficult to express in words, and is the result of c individual's long-term creation and accumulation. Implicit knowledge is not easy to recognize and difficult to measure its value or understood by other persons.

The more important point in the theory of knowledge management is that implicit knowledge is more valuable than explicit knowledge. Figuratively speaking, explicit knowledge can be said to be the "tip of the iceberg", while implicit knowledge is the large that is hidden in the bottom of the iceberg. Implicit knowledge is intellectual capital, the roots of trees to provide nutrition, while explicit knowledge is the fruit of the tree. Modern education lays too much emphasis on the short-term effect of explicit knowledge, 
which needs much to focus on developing students' implicit knowledge. In this sense, we need both the easily sharing explicit knowledge and the internal, creative implicit knowledge.

\section{Implicit knowledge externalization in the process of case compiling}

The process of the case compiling contains a great deal of knowledge externalization. In general case compiling, after finding a suitable case enterprise object, it will usually conduct interviews with a number of different objects. In addition to collecting data, especially the details of the situation and information, in each interview, it must do in-depth understanding of the various parties. Authors would like to try to grasp the narration of the parties, and to design continuous questions to force the parties to reflect on their deep-seated factors in thinking and behaviors.

In this regard, the application of reflection, probing and in-depth dialogue technique is necessary. Whether the written case is able to reproduce the context of decision-makers' choices or not and a wide range of influencing factors that describe the role, are the most critical for the excavation of implicit knowledge.

However, the externalization of implicit knowledge is not to make all information systematic and structured. In fact, for the effectiveness of the discussed cases, qualified cases topics and the content are personalized in principle, without suggestive colors or directions of misleading. At the same time, there are no so-called standards or logic program. In order to challenge students' data analysis capabilities, particularly in many cases information is written scattered. In dialogues of some cases, it does not eliminate the false and retain the true, and the leaves the students to do homework to distinguish the authenticity of the actual situation.

\section{Knowledge sharing in case teaching}

The whole process of a case teaching usually includes individual reading and research, team communication and research, classroom discussion and research and writing of after-class reports.

In the stage of individual research, students mainly understand the skeleton of the whole case and try to be familiar with case background and point out their own points of view through consulting other materials and specialists. This part integrates into students' personal related knowledge and partial knowledge of the related persons.

In the team research and discussion before class, because there are a few team members, members have lots of opportunities to speak. Moreover, the discussion form is informal, students care less about the mistakes and childish views. So, it is an indispensable part of case teaching. By the preparation of team, students, based on their own writing research reports add knowledge of other members of the team, in which there contains a great deal of implicit knowledge.

The discussion on the case in classroom is the key point of the case teaching activity and also the high point of the effect of case teaching developing. In the formal class, everybody tries their best to point out their view, expecting attention by others and at the same time they are curious about weather they can learn updated point of view from others or not. In the whole process of the discussion, what every one expresses is not the information of the case itself, while it is the judgment, insight and initiation base on personal experience that comes from individual's preparation and team research. The discussion on this part is the study of implicit knowledge, the advantages of knowledge sharing only in case teaching and the part that traditional teaching method can not replace.

Students' knowledge is mainly shared in the class of discussion, thus, how to urge every student positively participate in is very important. Teachers' role and duty in class at this time appears very important. He cannot lead the process of discussion and needs to urge every student to perform and makes the topic and content of not be uncontrollable. After the case discussion, usually there will not be coincident view and key, of course, teachers will not be proper to lead the results of case decision analysis. In fact, this is the real reflection of the uncertain decision in many actual enterprises.

The report made after the case is very important for learners after they sort out lots of explicit and implicit knowledge and internalize their own mind in the process of case teaching. And case report by proper ways being offered to all people in discussion to look through and read is also of great significance.

\section{Case teaching is the process of knowledge innovation}

New knowledge generates in the process of the change of explicit and implicit knowledge. In the four transformation processes of implicit to explicit knowledge, explicit to explicit knowledge, explicit to 
implicit knowledge and implicit to implicit knowledge, the first kind of transformation is the most effective way to generate knowledge. The implicit knowledge owned by a person is the core of the process of generating new knowledge and the generation of new knowledge, to a great extent, depends on the dynamic actions of the four modes. Therefore, if the dynamic interactions between the four modes increase, that is to say there are more people to participate in, knowledge in teams or organizations will appear "knowledge amplification". Knowledge thus improves from personal level to team level or organization level, even the level among different organization. Therefore, effective knowledge transformation process needs the frequent common interaction among different levels and the four modes. What is more, in order to make valuable implicit knowledge rapidly turn into explicit knowledge, a better way of interactively communicating and expressing our own knowledge is needed.

Compared with traditional teaching modes in the aspect of interactive communication, case teaching is an optimized communication which makes us gain knowledge more quickly and convenient. From the way of expressing one's own knowledge, in case teaching, it is good for the expression of implicit knowledge and generation of new knowledge by using ambiguous metaphor and story and using body language and charts of all kinds of depiction. At this moment, the real connotation forms different images in the minds of different participants even causes ambiguities. However, it is from these ambiguities, there is innovation. Because of the ambiguities, people will try to better define their own meaning and try to solve the existing contradiction.

In case teaching, the next step of the generation of new knowledge is analysis. In many speeches of different people, it makes the unclear thoughts structuring to solve the existing contradiction. Analysis is the transition from imagination to logic thoughts. However, enough communication and thought are the last step to make the very valuable implicit knowledge generate in individuals constantly update into implicit knowledge for individuals, every members of teams and classes. In a word, from the perspective of knowledge management theories, case teaching is an effective way to promote knowledge transition and realize knowledge innovation.

Case teaching does not intend to replace the traditional teaching methods on the whole; however, case teaching after all is a kind of "practical" learning process. It has its unique effect on cultivating students creative thinking mode and analysis and decision-making abilities in actual work.

\section{Case teaching is an effective process to urge knowledge transform}

Listening to and learning others' best practices are of course very important and valuable magic weapons. Lots of people thus think that the compiling and teaching of cases are for the experiences of successful management. However, to share the best experience is only a knowledge transformation mode of "from explicit to explicit". Many managers share others' best practices through participating in meetings, seminars, speech and researching on journals, but it is only a transitional aim. Explicit knowledge must turn into implicit knowledge very soon or its value will not exist any longer. Others' best practice is only a potential source of new knowledge. If one wants to make this kind of knowledge turn into later experience, judgment, initiation and insight, the most important thing is to make the created new knowledge internalized through frequent and two-way communication and cooperation among individuals, teams and inner organizations. From this significance, the turning of explicit knowledge into implicit knowledge is the true aim of case teaching.

All in all, from the theories of knowledge management, case teaching is an effective process to urge knowledge to transform and generate new knowledge.

\section{Conclusion}

Education, as the main way for knowledge spreading, includes not only the unilateral spreading, furthermore, it emphasizes more on multilateral interactions. From the analysis aspect of knowledge management, the highly participating case teaching has the important significance of knowledge sharing, knowledge transformation and knowledge innovation. Teachers should urge and take the advantage of case teaching to fully develop the main part position of students, thus the traditional teaching mode of "teachers say" can be changed. In the classroom, teachers try to make every student participate in the teaching and fully develop their consciousness, initiative and creativity so as to reach the aims and effects 
of cultivating and improving their abilities of self-thinking, linking theories with practice and solving problems.

\section{References}

[1] Chen, Y. Y., "Application of Case Teaching Method in Teaching," Academic Journal of Wuxi South Ocean College, 2008, 7 (4).

[2] Zheng, J. Z., "Case Teaching Guidance” Shanghai: East China Normal University Press. 2000.

[3] Yang, B., Zhao, C. J., "Research on Knowledge Management of Case Teaching," Academic Journal of University of Electronic Science and Technology, Social Science Edition. 2001, 7. 